\title{
3,4',7-0-trimethylquercetin Inhibits Invasion and Migration of Ovarian Cancer Cells
}

\author{
KOSEI YAMAUCHI ${ }^{1,2}$, SYEDA H. AFROZE ${ }^{1}$, TOHRU MITSUNAGA ${ }^{2}$, \\ TIMOTHY C. MCCORMICK ${ }^{3}$, THOMAS J. KUEHL ${ }^{3,4}$, \\ DAVID C. ZAWIEJA ${ }^{1}$ and MOHAMMAD N. UDDIN ${ }^{3,4,5}$
${ }^{1}$ Department of Medical Physiology, Texas A\&M Health Science Center College of Medicine, Temple, TX, U.S.A.;
${ }^{2}$ United Graduate School of Agricultural Science, Gifu University, Gifu, Japan;
Departments of ${ }^{3}$ Obstetrics and Gynecology, ${ }^{4}$ Pediatrics and ${ }^{5}$ Internal Medicine, Baylor Scott \& White Health/Texas A\&M Health Science Center College of Medicine, Temple, TX, U.S.A.

\begin{abstract}
Background/Aim: Methylquercetin, 3,4',7-Otrimethylquercetin (34'7TMQ), has been reported to inhibit metastasis. Recently, we demonstrated that 34'7TMQ inhibited the in vitro melanoma B16 cell metastatic activity. We evaluated the effect of 34'7TMQ on three ovarian cancer cells (SK-OV-3, CRL11731 and CRL1978). Materials and Methods: Proliferation, migration and invasion were measured in 34'7TMQ-treated ovarian cancer cells by commercially available kits. We also evaluated the expression of proliferating cell nuclear antigen (PCNA), urokinase plasminogen activator (uPA), plasminogen activator inhibitor 1 (PAI-1) and matrix metalloproteinase (MMP)-2 by western blot analysis. Results: 34'7TMQ inhibited ovarian cancer cell migration and invasion without effecting proliferation. Furthermore, 34'7TMQ inhibited the expression of $U P A$ and MMP-2; however, it had no effect on PAI-1 and PCNA. Conclusion: 34'7TMQ significantly regulates the expressions of protein to inhibit metastasis in ovarian cancers, while the regulatory effects of 34'7TMQ vary between different ovarian cancer cell lines.
\end{abstract}

It may surprise some that ovarian cancer, one of the most common cancer diagnoses women receive, has a higher mortality rate $(69 \%)$ than that of breast cancer $(19 \%)$. In fact, $75 \%$ of ovarian cancer metastasizes (mostly to the omentum)

This article is freely accessible online.

Correspondence to: Mohammad N. Uddin, Ph.D., Department of Obstetrics and Gynecology, Scott \& White Medical Center, 2401 South 31st Street, Temple, TX, 76508, U.S.A. Tel: +1 2547243624, Fax: +1 2547241046, e-mail: Mohammad.Uddin1@BSWHealth.org

Key Words: Ovarian cancer, anti-metastasis, anti-invasion, antimigration, methylquercetin. during its advanced stages (1). Matrix metalloproteinase (MMP)-2 is reported as an early regulator of ovarian cancer metastasis (2, 3). Urokinase plasminogen activator (uPA) and plasminogen activator inhibitor 1 (PAI-1) are suggested to play a significant role in metastasis, usually being involved in the conversion of pro-MMP-2 to its active form (4). Further, uPA and PAI-1 have been used as a target to search anti-metastasis agents. Benzyl isothiocyanate, including the dietary cruciferous vegetables, was reported to inhibit migration and invasion due to decreasing uPA expression in human colon cancer cells (5). Curcumin, a component of turmeric, and its derivatives were also reported to inhibit migration and down-regulate uPA expression (6). Diaryl esters of phosphonic-type were synthesized as potent uPA inhibitors (7).

Quercetin, which is a representative flavonoid, is a component of various fruits and vegetables (8-10). Recently, the pharmacological effects of quercetin have been studied for their positive impact on human health and it has since been confirmed that a variety of bioactivities, such as antioxidant, anti-inflammatory and anticancer effects, have been found within quercetin (11-13). It was also reported that quercetin inhibits migration and invasion of human hepatoma cells and prostate cancer cells $(14,15)$. Additionally, quercetin is also known to inhibit growth and metastasis in melanoma by suppressing the phosphorylation of c-Met downstream molecules including: p21-activated kinases, growth factor receptor-bound protein 2-associated-binding protein 1 and focal adhesion kinase relating to metastasis $(16-21)$. It is also well-known that quercetin suppresses uPA and other proteins relating to migration and invasion of human oral cancer cells (22). In our previous study (23), we isolated and identified two novel quercetin glycosides from Helminthostachys zeylanica root extract: 4'-O- $\beta$-Dglucopyranosyl-quercetin-3-O- $\beta$-D-glucopyranosyl-( $1 \rightarrow 4)$ $\beta$-D-glucopyranoside; and 4'-O- $\beta$-D-glucopyranosyl- $(1 \rightarrow 2)$ - 
$\beta$-D-glucopyranosyl-quercetin-3-O- $\beta$-D-glucopyranosyl$(1 \rightarrow 4)-\beta$-D-glucopyranoside).

Thus far, 19 quercetin derivatives have been synthesized from rutin as starting material $(24,25)$. The anti-migration and anti-proliferation activities of the 7 methylquercetin and quercetin glycoside on B16 melanoma cells were evaluated in our previous study (26). Among all the other quercetin derivatives, 3,4',7-O-trimethylquercetin (34'7TMQ) exhibits the most potent anti-migration activity with no cytotoxicity in human cells. Hence, we investigated the migration and invasion of 34'7TMQ using ovarian cancer cells; we also determined the expression of proteins, proliferating cell nuclear antigen (PCNA), MMP-2, uPA and PAI-1, which are involved in the metastasis and proliferation in the cancer cells.

\section{Materials and Methods}

General experimental procedures. Human ovarian cancer cells were purchased from Cell Biolabs (San Diego, CA, USA). Migration and Invasion assay kit (CBA-101-C) was purchased from Cell Biolabs and 2,3-Bis-(2-Methoxy-4-Nitro-5-Sulfophenyl)-2H-Tetrazolium-5Carboxanilide (XTT) cell viability assay kit was purchased from Thermo Fisher (San Diego, CA, USA). Antibodies against uPA (H140), PAI-1 (H-135), PCNA (PC10), $\beta$-actin (C4), MMP-2 (2C1), horseradish peroxidase (HRP)-conjugated anti-rabbit IgG donkey antibody (sc-2313) and HRP-conjugated anti-mouse IgG goat antibody (sc-2318) were purchased from Santa Cruz Biotechnology (Santa Cruz, CA, USA). Dulbecco's modified Eagle's medium (DMEM) and fetal bovine serum (FBS) were purchased from Gibco (Gaithersburg, MD, USA). Penicillin-streptomycin-amphotericin B cocktail (LS-1085) was purchased from LifeLine (Frederick, MD, USA). Cell lysis buffer was purchased from Cell Signaling Tech. (Beverly, MA, USA).

Cell culture. Three ovarian cancer cell lines, CRL-1978, CRL-11731 and SK-OV-3 (American Type Culture Collection, Manassas, VA, USA), were grown in DMEM supplemented with $10 \%$ FBS and penicillin-streptomycin-amphotericin B cocktail. Cells were cultured at $37^{\circ} \mathrm{C}$ in a humidified atmosphere of $5 \% \mathrm{CO}_{2}$.

Migration and invasion assay. Measurement of migration and invasion activity was performed using an assay kit (CBA-101-C; Cell Biolabs). Briefly, confluent cultures of ovarian cancer cells were removed using Accutase ${ }^{\circledR}$ (Sigma-Aldrich, St. Louis, MO. USA). Cell suspension containing $5.0 \times 10^{5}$ cells/well in $0.5 \%$ FBS DMEM was prepared. Dimethyl sulfoxide (DMSO) was used as the control and 34'7TMQ was added to the inside of each insert. A 500 $\mu \mathrm{l}$ of DMEM, including $10 \%$ FBS and 34'7TMQ, was added to the lower well of the plate and $300 \mu \mathrm{l}$ of cell suspension solution was loaded into a cell culture with the inserts placed into a 24 -well plate. The cells were incubated with the compound at $37^{\circ} \mathrm{C}$ for $24 \mathrm{~h}$. Cells migrating or invading to other sides of the inserts were stained and the absorbance of extracted solutions was measured at $560 \mathrm{~nm}$ using a microplate reader. Each experiment was repeated three times. The migration and invasion activities were expressed as a fold change against the control cells, treated with DMSO without sample materials.
Proliferation assay. Measurement of proliferation activity was performed using XTT regent. Ovarian cancer cells were used to determine cell viability of 34'7TMQ. The DMEM-containing 10\% FBS cultures were initiated in $96-$ well plates at $5.0 \times 104$ cells per well. Following incubation with compounds for $48 \mathrm{~h}$, the medium was then changed to the fresh medium containing XTT reagent. The plates were incubated in a humidified atmosphere of $5 \% \mathrm{CO}_{2}$ at $37^{\circ} \mathrm{C}$ for $4 \mathrm{~h}$. The absorbance was measured at $490 \mathrm{~nm}$ by using a microplate reader. Cell viability was expressed as a fold change against the control cells, treated with solvent DMSO without sample materials.

Western blot assay. Ovarian cancer cells treated with 34'7TMQ at 12.5-0 $\mu \mathrm{M}$ for 48 hours were lysed with cell lysis buffer containing a protease inhibitor cocktail at $0^{\circ} \mathrm{C}$ for $10 \mathrm{~min}$. Protein concentrations were determined using a bicinchoninic acid (BCA) protein assay kit (\#23227; Thermo) and a bovine serum albumin solution as a standard. Cell lysates were loaded at $10 \mu \mathrm{g}$ of protein per lane and separated by sodium dodecyl sulfate-polyacrylamide gel electrophoresis (SDS-PAGE) on Invitrogen ${ }^{\mathrm{TM}}$ Novex $^{\mathrm{TM}} \mathrm{NuPAGE}^{\mathrm{TM}}$ 4-12\% Bis-Tris gel (Fisher Scientific, Waltham, MA). Proteins were subsequently transferred onto a nitrocellulose membrane (Bio Rad, Hercules, CA, USA) using a wet transfer system for $2 \mathrm{~h}$. The membrane was blocked with $5 \%$ dry milk in tris-buffered saline Tween 20 (TBST) at $4^{\circ} \mathrm{C}$ for $2 \mathrm{~h}$. The membranes were incubated with dilutions of mouse monoclonal anti- $\beta$-actin $(1: 10,000)$, rabbit polyclonal anti-uPA (1: 500), rabbit polyclonal anti-PAI-1 (1:500), mouse monoclonal anti-PCNA $(1: 2,000)$ or mouse monoclonal antiMMP-2 (1:500) antibodies. Following overnight incubation at $4{ }^{\circ} \mathrm{C}$, the membranes were washed and incubated with 1:2,000 diluted HRP-conjugated secondary antibody for $2 \mathrm{~h}$. Following addition of the SuperSignal ${ }^{\circledR}$ substrate (Thermo), protein density was visualized using enhanced chemiluminescence detection system (LAS-4000; Fujifilm, Tokyo, Japan) and quantified by Image J Software ${ }^{\circledR}$ (https://imagj.nih.gov/ij/).

Statistical analysis. All data are expressed as means \pm SEM. values. Statistical significance of differences was evaluated using the Student's $t$-test. Data from methylquercetin-treated cells in in vitro experiments were compared with those from basal DMSO-treated controls using the Student's $t$-test with repeated measures as methylquercetin dosages varied within each experiment. Experiments were repeated five times to produce the replicates and data were expressed as means $\pm \mathrm{SD}$. A $p$-value of less than 0.05 was considered significant.

\section{Results}

The result of cell viability in Figure 1 showed that 34'7TMQ exhibited no effect on ovarian cancer cell proliferation. The effect of this compound on invasion and migration were investigated using a commercially available kit. Figures 2 and 3 show that 34'7TMQ inhibited migration and invasion of all ovarian cancer cell lines in a dose-dependent manner. Results also revealed that 34'7TMQ significantly inhibited invasion in CRL-1978 to 0.56-, 0.41- and 0.31-fold at 6.25, 12.5 and $25 \mu \mathrm{M}$, respectively, which is more potent than in the other cell lines. 
A



B

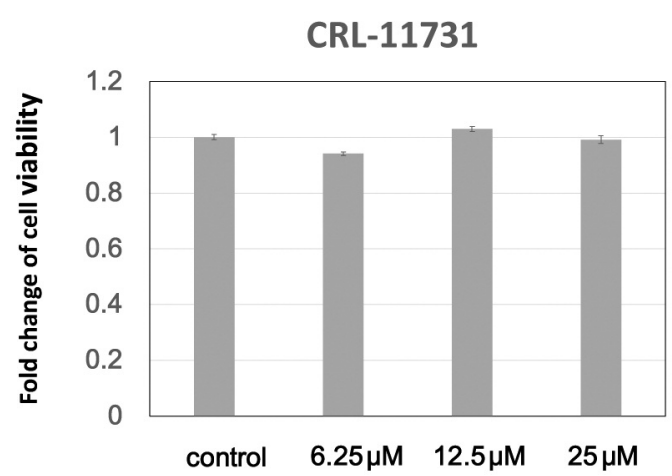

C

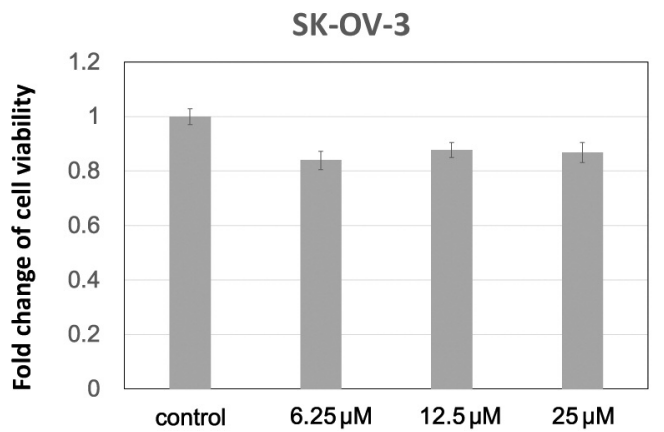

Figure 1. Cell viability of 3,4',7-O-trimethylquercetin (34'7TMQ)treated ovarian cancer cell lines. A: CRL-1978, B: CRL-11731, C: SKOV-3 treated with 334'7TMQ. Data are expressed as means $\pm S E M ; n=6$.

The protein expressions regarding cancer metastasis, using the three ovarian cancer cell lines, were investigated so as to elucidate the mechanism of the inhibitory effect on migration and invasion. The compound studied decreased uPA and MMP-2 in the three ovarian cancer cell lines (Figures 4, 5 and 6). Furthermore, the inhibitory effect of 34'7TMQ on uPA expression in SK-OV-3 cell line was particularly potent, even at $3.125 \mu \mathrm{M}$ concentration (Figure 4). In contrast, PAI-1 was increased in CRL-1978 more than 8 times by $12.5 \mu \mathrm{M}$ of 34'7TMQ
A

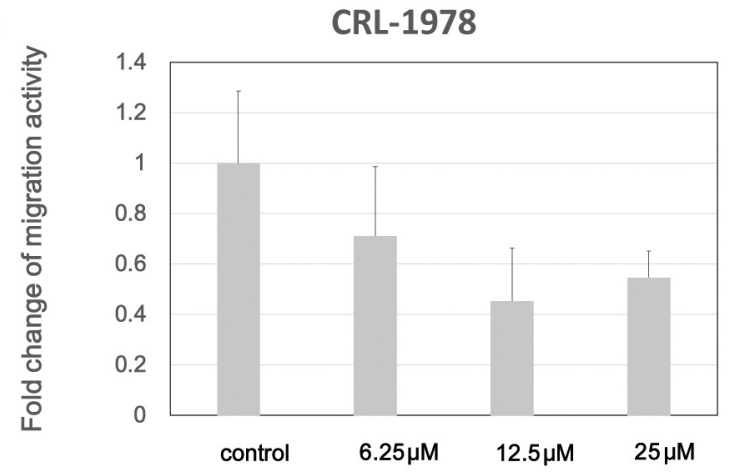

B

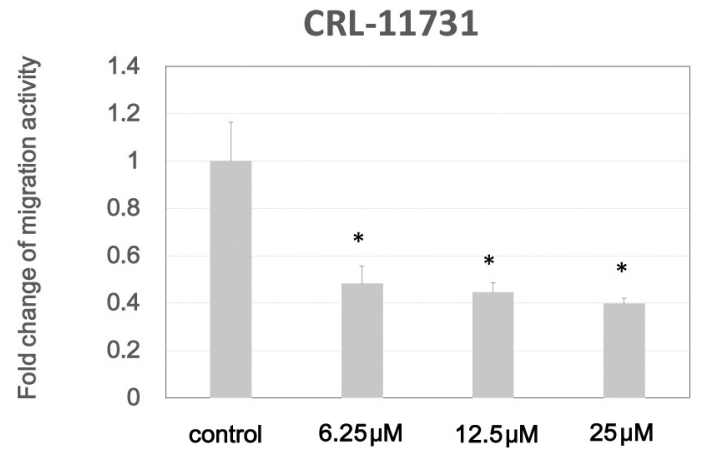

C

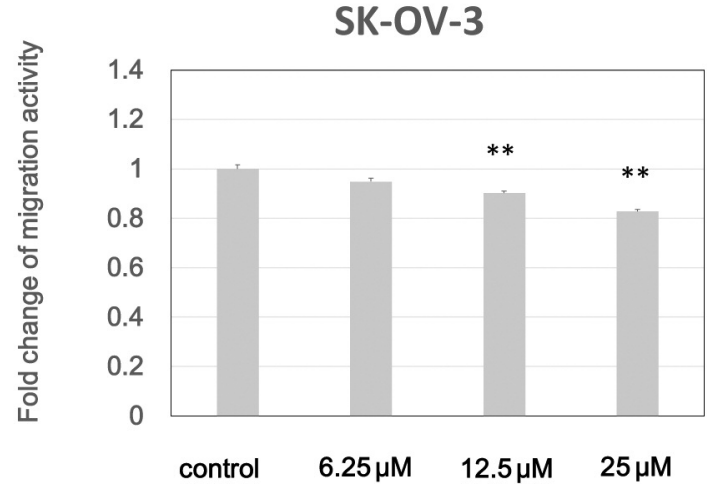

Figure 2. Migration activity of 3,4',7-O-trimethylquercetin (34'7TMQ) in 3 ovarian cancer cell lines (A: CRL-1978, B: CRL-11731, C: SK-OV3). Data are expressed as means \pm SEM; $n=3 ; * p \leq 0.05 ; * * p \leq 0.01$ compared to respective control values.

treatment, that had a different effect on the other cell lines (Figure 6).

\section{Discussion}

In the worldwide search for anticancer agents, nature has often proved to be a helpful ally. For instance, Chinese herbs and ingredients have been studied for their role as anti-hepatic cell cancer agents (27). One such ingredient found in traditional 
A

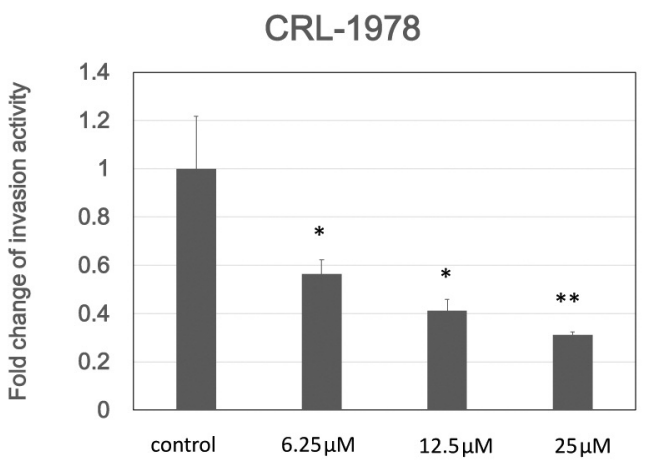

B



C

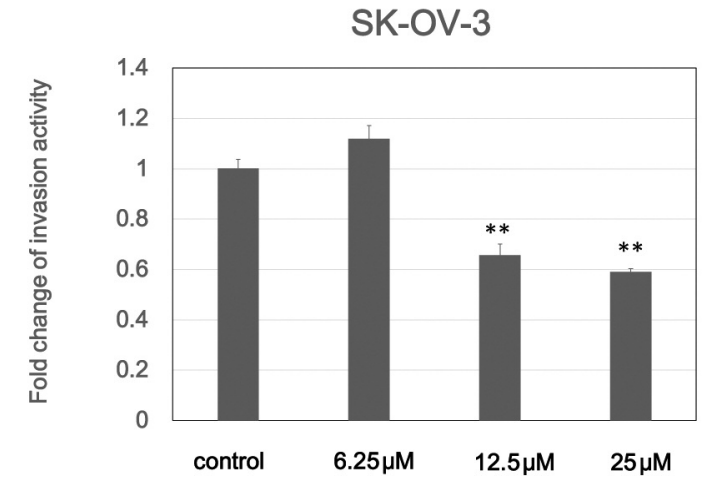

Figure 3. Invasion activity of 3,4',7-O-trimethylquercetin (34'7TMQ) in three ovarian cancer cell lines (A: CRL-1978, B: CRL-11731, C: SK$O V-3)$. Data are expressed as means \pm SEM; $n=3 ; * p \leq 0.05 ; * * p \leq 0.01$ compared to respective control values.

Chinese medicine is a compound called cinobufotalin; it is known for being a cardiotonic steroid and its chemical properties have been investigated regarding their anticancer potential. Mushrooms are also a source of anticancer agents; for example, lentinan, hispolon, theanine, grifolin, antroquinonol and cordycepin were isolated from mushrooms as anticancer agents (32). The anticancer effects of polyphenols in natural products have also been confirmed. For example, curcumin is one of the most beneficial polyphenols and, in Southeast Asia, the compound is traditionally mixed with turmeric; the result has become a very popular medicine. Curcumin inhibits proliferation, migration and invasion by modulating expression of transcription factors, cell cycle regulatory proteins and protein kinases (33).

We have focused on the anticancer effect of quercetin derivatives, which are the polyphenol representatives in natural products. In our previous study, 34'7TMQ exhibited anti-migration effects in mouse B16 melanoma cells. The anti-metastasis effects, as well as protein expressions regarding metastasis in ovarian cancer cell lines treated with methylquercetin, were evaluated in this study.

As shown in Figure 1, 34'7TMQ showed no cytotoxicity in three ovarian cancer cell lines. This compound inhibited migration and invasion in all ovarian cancer cell lines in a dose-dependent manner (Figures 2 and 3). Furthermore, 34'7TMQ inhibited invasion in CRL-1978 more effectively than the other cell lines (0.56-, 0.41 - and 0.31 -fold at 6.25, 12.5 , and $25 \mu \mathrm{M}$, respectively). Migration inhibitory activity of 34'7TMQ for SK-OV-3 was lower than the other cell lines, which is $0.95-, 0.90$ - and 0.83 -fold at the same concentrations. 34'7TMQ inhibited invasion more potently than migration in SK-OV-3. These results indicated that 34'7TMQ has the potential to inhibit metastasis in ovarian cancers, as well as B16 melanoma cells, which was evaluated in our previous report. We investigated the protein expressions involved in cancer metastasis using the three ovarian cancer cell lines in order to clarify the mechanism of the inhibitory effect on migration and invasion. PCNA, relating to cell proliferation, showed no effect by the 34'7TMQ treatment in the ovarian cancers. The compound studied herein decreased UPA and MMP-2 in the three ovarian cancer cell lines and potently inhibited uPA expression in SK-OV-3, resulting in deactivating MMPs (Figure 4). This may be the reason 34'7TMQ inhibited invasion more potently than migration in SK-OV-3 via inhibiting the degradation of MMPs. Moreover, we found that 34'7TMQ treatment also decreased uPA and MMP-2 in CRL-11731 and CRL-1978 (Figures 5 and 6). Interestingly, PAI-1 was increased in CRL-1978 by the 34'7TMQ treatment, which resulted in a different effect from all the other cell lines (Figure 6). This result suggested that the compound studied acts differentially in the various ovarian cancer cell lines. PAI-1 expression is activated via extracellular signal-regulated kinase and nuclear factor-kappa B as it relates to inflammation (34). The mineralocorticoid receptor and aldosterone are also reported to be involved in PAI-1 expression (35). The expressions of these proteins and hormones regarding PAI-1 expressions may be different in CRL-1978 than in the other two ovarian cancer cell lines. Additionally, the double-effect on PAI-1 and uPA expression may cause the invasion inhibitory activity in CRL-1978 to be more potent there than in any other cell lines. 
A<smiles>COc1cc(O)c2c(c1)OC(c1ccc(OC)c(O)c1)C(O)C2=O</smiles>

34'7TMQ



B

SK-OV-3

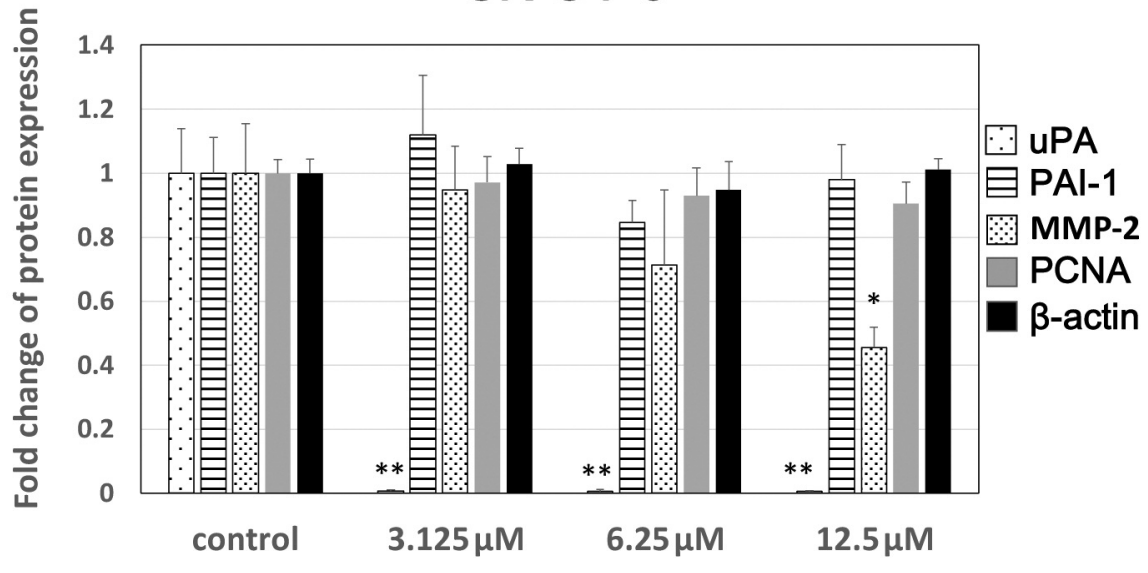

Figure 4. The effect 3,4',7-O-trimethylquercetin (34'7TMQ) on urokinase plasminogen activator (uPA), plasminogen activator inhibitor 1 (PAI-1), matrix metalloproteinase (MMP)-2 and proliferating cell nuclear antigen (PCNA) expression in SK-OV-3 ovarian cancer cells treated with 34'7TMQ for $48 \mathrm{~h}$. (A) Representative blot for each protein; (B) Fold change of the band density. Data are expressed as means \pm SEM; $n=3$; * $\leq 0.05$; ** $\leq \leq 0.01$ compared to respective control values.

A<smiles>COc1cc(O)c2c(=O)c(C)c(-c3ccc(OC)c(O)c3)oc2c1</smiles>

34'7TMQ

control $3.125 \quad 6.2512 .5(\mu \mathrm{M})$

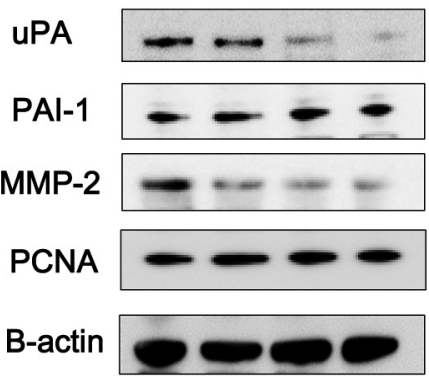

B

CRL-11731

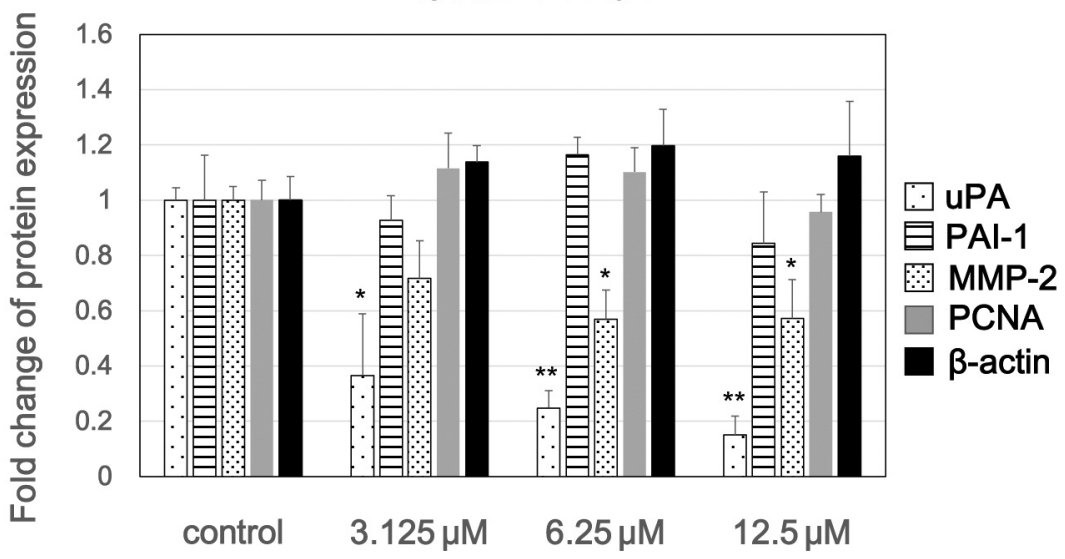

Figure 5. The effect 3,4',7-O-trimethylquercetin (34'7TMQ) on urokinase plasminogen activator (uPA), plasminogen activator inhibitor 1 (PAI-1), matrix metalloproteinase (MMP)-2 and proliferating cell nuclear antigen (PCNA) expression in CRL-11731 ovarian cancer cells treated with 34'7TMQ for $48 \mathrm{~h}$. (A) Representative blot for each protein; (B) Fold change of the band density. Data are expressed as means $\pm S E M ; n=3 ; * p \leq 0.05$; $* * p \leq 0.01$ compared to respective control values.

We discovered that 34'7TMQ inhibited migration and invasion in three ovarian cancer cell lines, CRL-1978, CRL11731 and SK-OV-3, without cytotoxicity. We also found that UPA and MMP-2 were decreased by 34'7TMQ in the three ovarian cancer cell lines. 34'7TMQ caused an increase in PAI-1 inactivating uPA in CRL-1978, which may have resulted in more potent invasion inhibitory activity than in the other ovarian cancer cell lines. Additionally, preclinical evaluation of 34'7TMQ on nude mice using a tumor xenograft model is underway in our lab. The discovery of the 
A<smiles>COc1ccc(-c2oc3cc(OC)cc(O)c3c(=O)c2O)c(O)c1</smiles>

34'7TMQ

control $3.1256 .2512 .5(\mu \mathrm{M})$

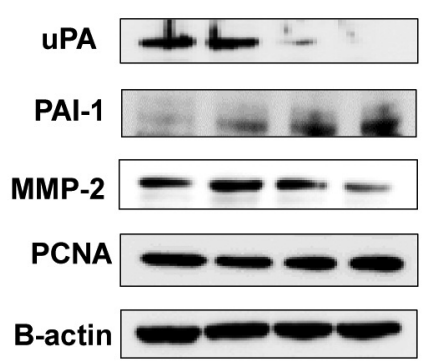

B



Figure 6. The effect 3,4',7-O-trimethylquercetin (34'7TMQ) on urokinase plasminogen activator (uPA), plasminogen activator inhibitor 1 (PAI-1), matrix metalloproteinase (MMP)-2 and proliferating cell nuclear antigen (PCNA) expression in CRL-1978 ovarian cancer cells treated with 34'7TMQ for 48 h. (A) Representative blot for each protein; (B) Fold change of the band density. Data are expressed as means $\pm S E M$; $n=3$; * $p \leq 0.05$; ${ }^{* *} p \leq 0.01$ compared to respective control values.

novel anti-metastatic activity of 34'7TMQ in ovarian cancer cells supports further research into its potential antimetastasis applications or possible uses for such compounds as anticancer agents.

\section{Conflicts of Interest}

All Authors have read the Journal's policy on disclosure of potential conflicts of interest and have none to declare.

\section{Acknowledgements}

The Authors of this paper wish to thank Mr. Terrynce C. McKeown in the Baylor Scott \& White Health Publication Office for providing assistance with the editing and formatting of this manuscript. Funding of this work was supported by Japan Society for the Promotion of Science (JSPS) postdoctoral fellowship for research abroad (KY) and by The Discovery Foundation, (MNU) and Grimes Family Foundation Endowment in Gynecologic Oncology (MNU). All authors have read the Journal's authorship agreement.

\section{References}

1 Lengyel E: Ovarian cancer development and metastasis. Am J Pathol 177(3): 1053-1064, 2010.

2 Kenny HA, Kaur S, Coussens L and Lengyel E: The initial steps of ovarian cancer cell metastasis are mediated by MMP-2 cleavage of vitronectin and fibronectin. J Clin Invest 118(4): 1367-1379, 2008.
3 Kenny HA and Lengyel E: MMP-2 functions as an early response protein in ovarian cancer metastasis. Cell Cycle 8(5): 683-688, 2009.

4 Schmalfeldt B, Prechtel D, Härting K, Späthe K, Rutke S, Konik E, Fridman R, Berger U, Schmitt M, Kuhn W and Lengyel E: Increased expression of matrix metalloproteinases (MMP)-2, MMP-9 and the urokinase-type plasminogen activator is associated with progression from benign to advanced ovarian cancer. Clin Cancer Res 7(8): 2396-2404, 2001.

5 Lai KC, Huang AC, Hsu SC, Kuo CL, Yang JS, Wu S and Chung GL: Benzyl isothiocyanate (BITC) inhibits migration and invasion of human colon cancer HT29 cells by inhibiting matrix metalloproteinase-2/-9 and urokinase plasminogen (uPA) through PKC and MAPK signaling pathway. J Agric Food Chem 58(5): 2935-2942, 2010.

6 Yodkeeree S, Chaiwangyen W, Garbisa S and Limtrakul P: Curcumin, demethoxycurcumin and bisdemethoxycurcumin differentially inhibit cancer cell invasion through the downregulation of MMPs and uPA. J Nutr Biochem 20(2): 87-95, 2009.

7 Sieńczyk M and Oleksyszyn J: Inhibition of trypsin and urokinase by Cbz-amino(4-guanidinophenyl)methanephosphonate aromatic ester derivatives: The influence of the ester group on their biological activity. Bioorg Med Chem Lett 16(11): 28862890, 2006.

8 Hertog MGL, Hollman PCH and Katan MB: Content of potentially anticarcinogenic flavonoids of 28 vegetables and 9 fruits commonly consumed in the Netherlands. J Agric Food Chem 40(12): 2379-2383, 1992.

9 Hollman PCH and Katan MB: Dietary flavonoids: Intake, health effects and bioavailability. Food Chem Toxicol 37(9-10): 937942, 1999. 
10 Manach C, Scalbert A, Morand C, Rémésy C and Jimenez L: Polyphenols: Food sources and bioavailability. Am J Clin Nutr 79(5): 727-747, 2004.

11 Gibellini L, Pinti M, Nasi M, De Biasi S, Roat E, Bertoncelli L and Cossarizza A: Interfering with ROS metabolism in cancer cells: The potential role of quercetin. Cancers (Basel) 2(2): 1288-1311, 2010.

12 Chen QX and Kubo I: Kinetics of mushroom tyrosinase inhibition by quercetin. J Agric Food Chem 50(14): 4108-4112, 2002.

13 Jackson JK, Higo T, Hunter WL and Burt HM: The antioxidants curcumin and quercetin inhibit inflammatory processes associated with arthritis. Inflamm Res 55(4): 168-175, 2006.

14 Lee WJ, Wu LF, Chen WK, Wang CJ and Tseng TH: Inhibitory effect of luteolin on hepatocyte growth factor/scatter factorinduced HepG2 cell invasion involving both MAPK/ERKs and PI3K-Akt pathways. Chem Biol Interact 160(2): 123-133, 2006.

15 Senthilkumar K, Arunkumar R, Elumalai P, Sharmila G, Gunadharini DN, Banudevi S, Krishnamoorthy G, Benson CS and Arunakaran J: Quercetin inhibits invasion, migration and signalling molecules involved in cell survival and proliferation of prostate cancer cell line (PC-3). Cell Biochem Funct 29(2): 87-95, 2011.

16 Piantelli M, Maggiano N, Ricci R, Larocca LM, Capelli A, Scambia G, Natali PG and Ranelletti FO: Tamoxifen and quercetin interact with type II estrogen binding sites and inhibit the growth of human melanoma cells. J Invest Dermatol 105(2): 248-253, 1995.

17 Rosner K, Ropke C, Pless V and Skovgaard GL: Late type apoptosis and apoptosis free lethal effect of quercetin in human melanoma. Biosci Biotechnol Biochem 70(9): 2169-2177, 2006.

18 Loizzo MR, Said A, Tundis R, Hawas UW, Rashed K, Menichini F, Frega NG and Menichini F: Antioxidant and antiproliferative activity of Diospyros lotus L. extract and isolated compounds. Plant Foods Hum Nutr 64(4): 264-270, 2009.

19 Rosner K, Ropke C, Pless V and Skovgaard GL: Late type apoptosis and apoptosis free lethal effect of quercetin in human melanoma. Biosci Biotechnol Biochem 70(9): 2169-2177, 2006.

20 Caltagirone S, Rossi C, Poggi A, Ranelletti FO, Natali PG, Brunetti M, Aiello FB and Piantelli M: Flavonoids apigenin and quercetin inhibit melanoma growth and metastatic potential. Int J Cancer 87(4): 595-600, 2000.

21 Cao HH, Cheng CY, Su T, Fu XQ, Guo H, Li T, Tse AK, Kwan GY, Yu H and Yu ZL: Quercetin inhibits HGF/c-Met signaling and HGF-stimulated melanoma cell migration and invasion. Mol Cancer 14(14): 103, 2015.

22 Lai WW1, Hsu SC, Chueh FS, Chen YY, Yang JS, Lin JP, Lien JC, Tsai $\mathrm{CH}$ and Chung JG: Quercetin inhibits migration and invasion of SAS human oral cancer cells through inhibition of NF- $\mathrm{kB}$ and matrix metalloproteinase-2/-9 signaling pathways. Anticancer Res 33(5): 1941-1950, 2013.

23 Yamauchi K, Mitsunaga T and Batubara I: Novel quercetin glucosides from Helminthostachys zeylanica root and acceleratory activity of melanin biosynthesis. J Nat Med 67(2): 369-374, 2013.
24 Yamauchi K, Mitsunaga T and Batubara I: Synthesis of quercetin glycosides and their melanogenesis stimulatory activity in B16 melanoma cells. Bioorg Med Chem 22(3): 937-944, 2014.

25 Yamauchi K, Mitsunaga T, Inagaki M and Suzuki T: Synthesized quercetin derivatives stimulate melanogenesis in B16 melanoma cells by influencing the expression of melanin biosynthesis proteins MITF and p38 MAPK. Bioorg Med Chem 22(13): 3331-3340, 2014.

26 Yamauchi K, Mitsunaga T, Afroze HS and Uddin MN: Structureactivity relationships of methylquercetin on anti-migration and anti-proliferation activity in B16 melanoma cells. Anticancer Res 37(4): 1575-1579, 2017.

27 Chen T, Li D, Fu YL and Hu W: Screening of QHF formula for effective ingredients from Chinese herbs and its anti-hepatic cell cancer effect in combination with chemotherapy. Chin Med J (Engl) 121(4): 363-368, 2008.

28 Emam H, Zhao QL, Furusawa Y, Refatt A, Ahmed K, Kadowaki $\mathrm{M}$ and Kondo T: Apoptotic cell death by the novel natural compound, cinobufotalin. Chem Biol Interact 199(3): 154-160, 2012.

29 Kai S, Lu JH, Hui PP and Zhao H: Pre-clinical evaluation of cinobufotalin as a potential anti-lung cancer agent. Biochem Biophys Res Commun 452(3): 768-774, 2014.

30 McDowell A, Afroze SH, Tobin R, McCormick TC, NewellRogers MK, Zawieja DC, Kuehl TJ and MN Uddin: Cinobufotalin as a novel agent to inhibit in vitro epithelial ovarian cancer cell proliferation, migration and invasion. Open J Obstet Gynecol 6(6): 343-351, 2016.

31 Lee IC and Choi BY: Withaferin-A: A natural anticancer agent with pleiotropic mechanisms of action. Int J Mol Sci 17(3): 290, 2016.

32 Patel S and Goyal A: Recent developments in mushrooms as anticancer therapeutics: A review. Biotech 2(1): 1-15, 2012.

33 Pavan AR, Silva GD, Jornada DH, Chiba DE, Fernandes GF, Man Chin C and Dos Santos JL: Unraveling the anticancer effect of curcumin and resveratrol. Nutrients 8(11): piie628, 2016.

34 Gillespie E, Leeman SE, Watts LA, Coukos JA, O'Brien MJ, Cerda SR, Farraye FA and Stucchi AF: Plasminogen activator inhibitor-1 is increased in colonic epithelial cells from patients with colitis-associated cancer. J Crohns Colitis 7(5): 403-411, 2013.

35 Marney AM and Brown NJ: Aldosterone and end-organ damage. Clin Sci (Lond) 113(6): 267-278, 2007.
Received April 17, 2017

Revised April 28, 2017

Accepted May 2, 2017 